\title{
Long Noncoding RNAs as Enhancers of Gene Expression
}

\author{
U.A. Ørom, ${ }^{1}$ T. Derrien, ${ }^{2}$ R. Guigo,${ }^{2}$ R. ShiekHatTaR ${ }^{1-3}$ \\ ${ }^{1}$ The Wistar Institute, Philadelphia, Pennsylvania 19104; ${ }^{2}$ Institució Catalana de Recerca $i$ Estudis \\ Avançats (ICREA), Barcelona, Spain 08010; ${ }^{3}$ Centre for Genomic Regulation (CRG), \\ Universitat Pompeu Fabra (UPF), Barcelona, Spain 08003 \\ Correspondence: shiekhattar@wistar.org
}

\begin{abstract}
The human genome contains thousands of long noncoding RNAs (ncRNAs) transcribed from diverse genomic locations. A large set of long ncRNAs is transcribed independent of protein-coding genes. We have used the GENCODE annotation of the human genome to identify 3019 long ncRNAs expressed in various human cell lines and tissue. This set of long ncRNAs responds to differentiation signals in primary human keratinocytes and is coexpressed with important regulators of keratinocyte development. Depletion of a number of these long ncRNAs leads to the repression of specific genes in their surrounding locus, supportive of an activating function for ncRNAs. Using reporter assays, we confirmed such activating function and show that such transcriptional enhancement is mediated through the long ncRNA transcripts. Our studies show that long ncRNAs exhibit functions similar to classically defined enhancers, through an RNA-dependent mechanism.
\end{abstract}

Most of the mammalian genome is transcribed, yet only $\sim 2 \%-5 \%$ encode for protein-coding genes (Cheng et al. 2005; Birney et al. 2007; Kapranov et al. 2007). Such noncoding transcripts are expressed from diverse loci. A large class of noncoding transcripts contains an independent genomic structure. However, many other noncoding RNAs (ncRNAs) are transcribed antisense to protein-coding genes, within intronic sequences, and at times close to transcription start sites of protein-coding genes (Kapranov et al. 2007; Rinn et al. 2007; Core and Lis 2008; Preker et al. 2008; Seila et al. 2008; Guttman et al. 2009).

Long ncRNAs may function in diverse biological pathways and most likely include numerous functional classes involved in different aspects of cellular biology. Many long ncRNAs are spliced, polyadenylated, and mirror properties of protein-coding genes without having a functional open reading frame (Guttman et al. 2009; Ørom et al. 2010). However, there have been reports of other long ncRNAs that are nonpolyadenylated and show various properties distinct from protein-coding genes (Kim et al. 2010).

A number of functional studies have identified a role for long ncRNAs in transcriptional silencing in processes such as imprinting and $\mathrm{X}$ inactivation (Wan and Bartolomei 2008). Such functions of long ncRNAs are shown to be mediated in cis. However, a recent study using tiling arrays of the Hox cluster has identified a long ncRNA involved in trans regulation of gene expression (Rinn et al. 2007). Moreover, the extensions of these studies in mouse (Guttman et al. 2009) and human (Khalil et al. 2009) have revealed a class of long ncRNAs based on chromatin marks termed "lincRNA" (long intervening ncRNA). In a more recent study, a set of long ncRNAs was described that are transcribed from predicted enhancer regions and are shown to be dependent on the transcription of their surrounding genes (Kim et al. 2010). We have found a set of long ncRNAs that are transcribed from their independ- ent loci and function to enhance the expression of their neighboring protein-coding genes (Ørom et al. 2010). These results extend the findings that long ncRNAs are associated with enhancer regions in the human genome.

\section{IDENTIFYING LONG NCRNAS FROM ENCODE DATA}

We used the ENCODE annotation of the human genome (Harrow et al. 2006) performed by human and vertebrate analysis and annotation (HAVANA) group at Sanger Institute to identify a set of 3019 long ncRNAs transcribed from regions not overlapping protein-coding genes. At the time of the analysis, the ENCODE annotation covered onethird of the human genome. We subtracted all transcripts mapping within $1 \mathrm{~kb}$ of annotated protein-coding genes to avoid promoter- and 3'-associated transcripts (Core and Lis 2008; Preker et al. 2008; Seila et al. 2008). Moreover, all known ncRNAs were eliminated from our collection of long ncRNAs. Using this approach, we identified 2286 genomic loci encoding 3019 transcripts that are putative long ncRNAs. Computational analyses of potential open reading frames and protein-coding capacity using GeneID (Parra et al. 2000; Blanco et al. 2007) support the HAVANA annotation as noncoding (Fig. 1A).

Comparison of the set of long ncRNA transcripts with protein-coding RNAs and ancestral repeats shows the conservation of the long ncRNAs to be less than that of protein-coding genes, but more than that of ancient repeats (Fig. 1B) used to estimate neutral evolution (Lunter et al. 2006; Ponjavic et al. 2007). Analysis of the promoter regions of the long ncRNAs shows a similar trend as for the transcripts (Fig. 1C). These conservation rates are in concordance with results in the mouse genome (Guttman et al. 2009; Marques and Ponting 2009; Ponting et al. 2009) and are the reflection of selective constraints acting to maintain the long ncRNA sequences. 
A

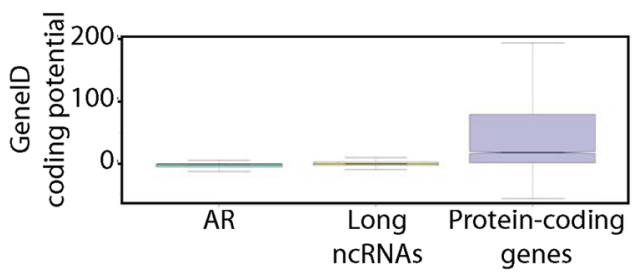

C

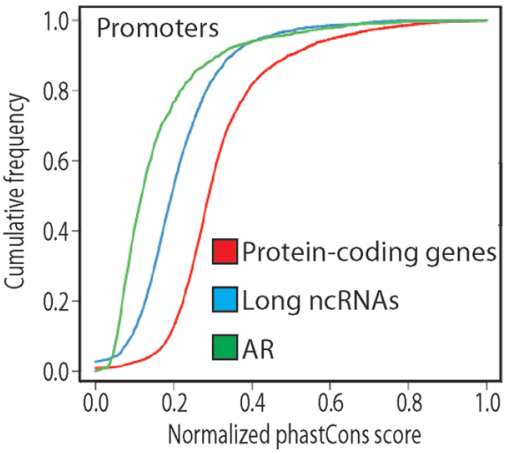

B

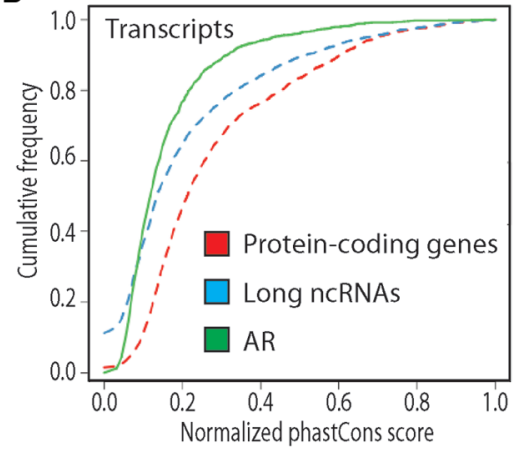

Figure 1. Coding potential and conservation of long ncRNAs. (A) Analysis of coding potential using GeneID of ancestral repeats (ARs), long ncRNAs, and protein-coding genes. $(B)$ Conservation analysis of transcript sequence; $(C)$ conservation analysis of promoter regions showing the cumulative frequency as a function of normalized phastCons score. (Reprinted, with permission, from Ørom et al. 2010 [CElsevier].)

\section{LONG NCRNAS SHOW CHARACTERISTICS SIMILAR TO PROTEIN-CODING GENES}

Analysis of our defined set of long ncRNA transcripts shows that they exhibit a distinct pattern of exon-intron structure from that of protein-coding genes (Fig. 2A). Many protein-coding genes contain more than 15 exons, whereas around half of the annotated long ncRNAs we have analyzed contain only two exons. To further compare our ncRNAs with protein-coding genes, we used recent evidence for the occurrence of trimethyl lysine 4 of histone $\mathrm{H} 3$ (H3K4me3) on the promoter of actively transcribed genes and trimethyl lysine 36 of histone H3 (H3K36me3) along the body of the genes (Mikkelsen et al. 2007; Guttman et al. 2009). Analysis of these chromatin marks on the promoters and along the body of the genes of the
A

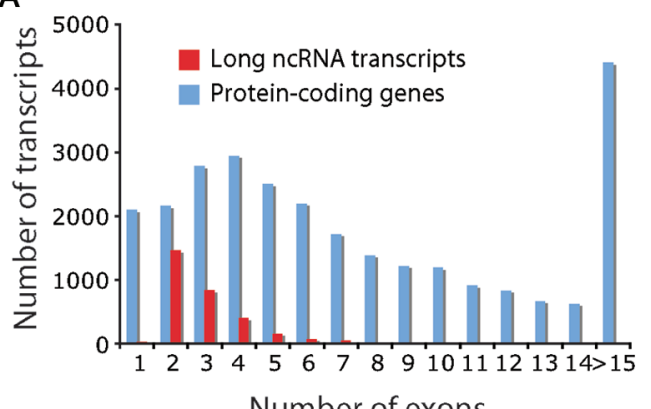

C

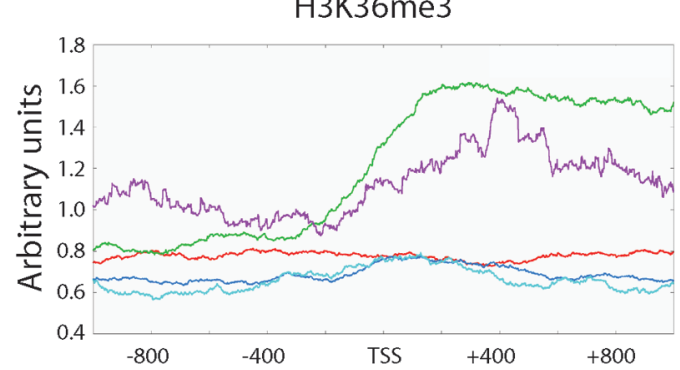

B
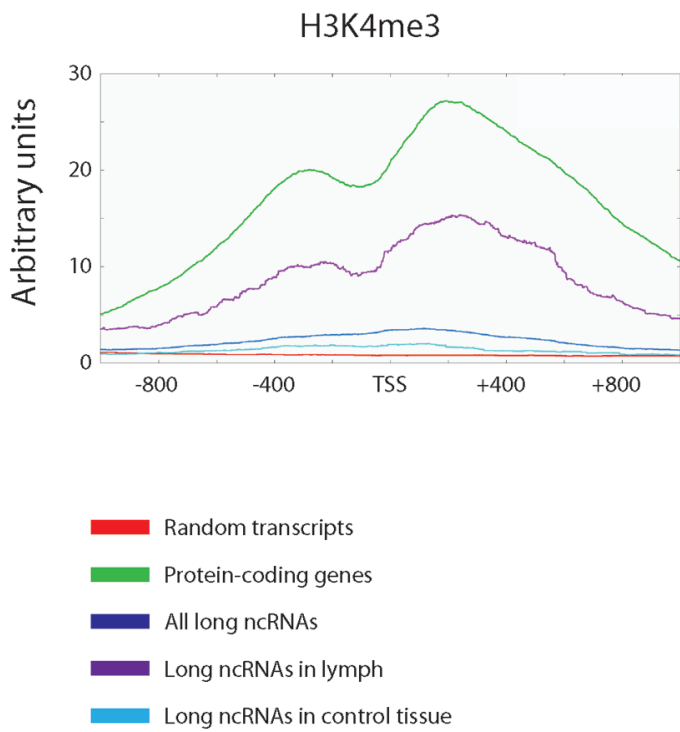

Figure 2. Characteristics of long ncRNAs. $(A)$ The number of exons for long ncRNAs and protein-coding genes is shown on the $x$ axis with corresponding counts for each number of exons. Most monoexonic long ncRNAs have been excluded from the HAVANA annotation as potential transcriptional noise. $(B) \mathrm{H} 3 \mathrm{~K} 4 \mathrm{me} 3$ and $(C) \mathrm{H} 3 \mathrm{~K} 36 \mathrm{me} 3$ around the transcription start site (TSS) of expressed and nonexpressed long ncRNAs and protein-coding genes in lymph. Numbers show distance in base pairs relative to the transcription start site. (Reprinted, with permission, from Ørom et al. 2010 [CElsevier].) 
long ncRNAs using available chromatin immunoprecipitation-sequencing data from $\mathrm{CD}^{+} \mathrm{T}$ cells (Barski et al. 2007) indicate that the GENCODE set of long ncRNAs expressed in lymph displays chromatin marks similar to those of expressed protein-coding genes (Fig. 2B,C).

\section{LONG NCRNAS ARE REGULATED IN KERATINOCYTE DEVELOPMENT}

To determine the long ncRNA response to external stimuli, we developed expression arrays for the set of 3019 long ncRNAs. We isolated RNA from primary human keratinocytes before or following differentiation with TPA (12-O-tetradecanoylphorbol-13-acetate) and analyzed them for expression levels of long ncRNAs and mRNAs using custom-made microarrays or whole-genome expression arrays from Agilent. We could detect 687 of the 3019 long ncRNAs in keratinocytes, of which 104 show differential expression following induction with TPA (Fig. 3A). For comparison, 1975 mRNAs are detected on the wholegenome arrays, of which 4107 are differentially expressed following differentiation (Fig. 3A). Although protein-cod-

A

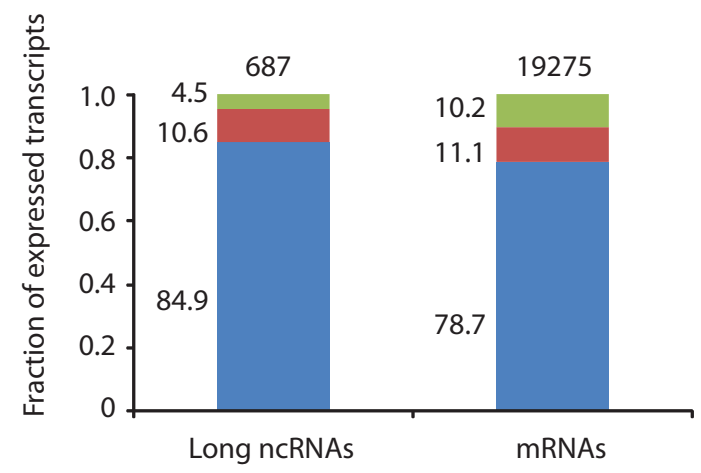

Not changed

Induced

Repressed
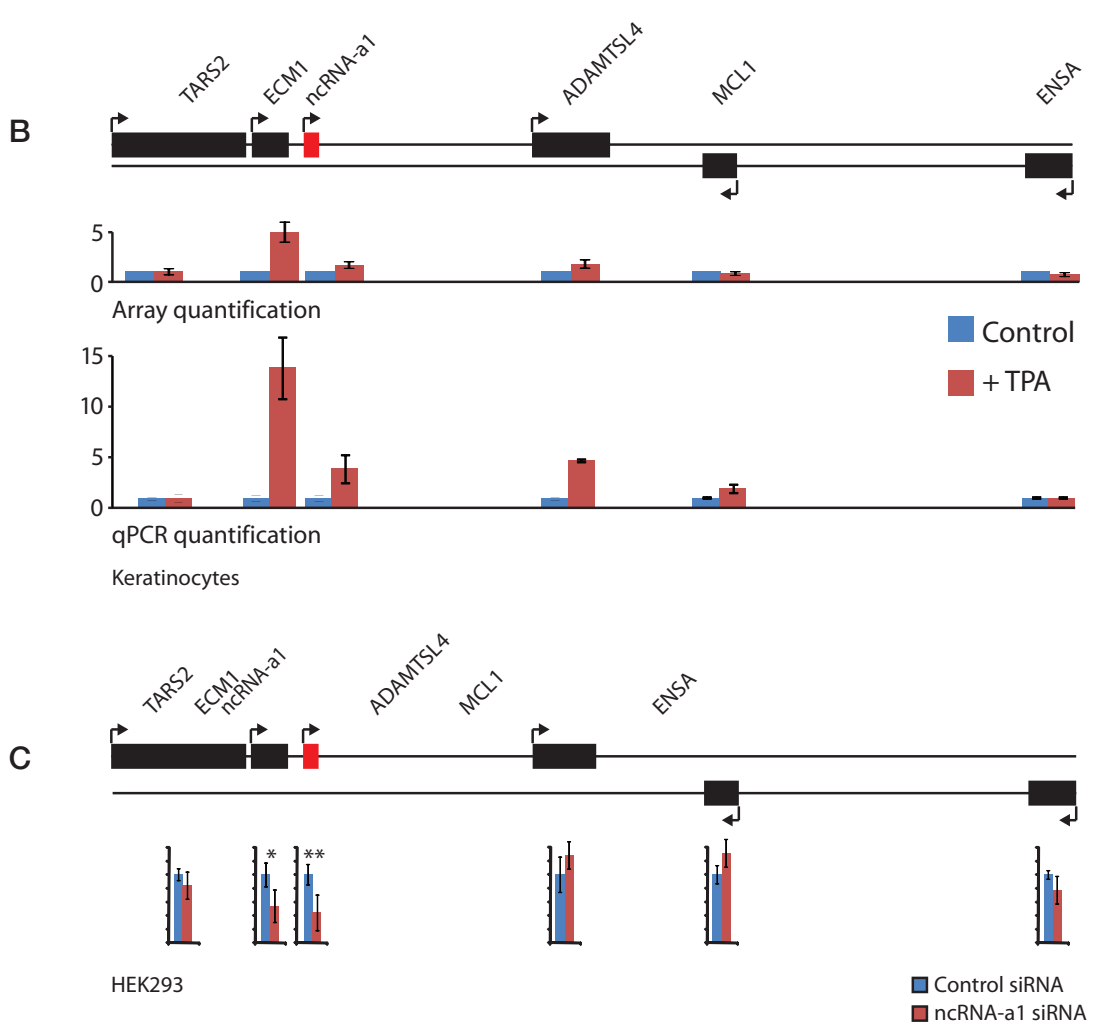

Figure 3. Long ncRNAs are differentially expressed in differentiation. Long ncRNAs and protein-coding genes (mRNA) expressed in keratinocytes and differentially expressed following differentiation with TPA. (A) Blue portions of the bars show the nondifferentially expressed transcripts, red portions represent the genes induced, and green portions the genes repressed, following induction of differentiation with TPA. Numbers to the left of the bars show the percentages of all expressed transcripts. Numbers above the bars show the total number of detected transcripts. $(B)$ ECM1 locus with relative expression levels before and after differentiation with TPA, as determined by microarray analysis (upper panel) and quantitative polymerase chain reaction (qPCR) (lower panel). (C) Knockdown of ncRNA-a 1 in 293 cells and effects on the surrounding locus, as determined by qPCR. $(* *) p<0.01 ;(*) p<0.05$ with one-tailed Student's $t$-test. (Thick black bars) Gene-encoding regions, (arrows) transcriptional directions. (Reprinted, with permission, from Ørom et al. 2010 [CElsevier].) 
ing genes display a similar percent of genes (50\%) that are induced or repressed following differentiation, $>70 \%$ of the differentially expressed long ncRNAs are induced as a consequence of differentiation (Fig. 3A). Analysis of the protein-coding genes surrounding the loci of induced long ncRNAs shows that many of these are involved in keratinocyte differentiation and extracellular matrix. Interestingly, as shown in Figure 3B, a differentially expressed long ncRNA resides in a locus with a protein-coding gene, ECM1, which is also differentially induced following differentiation. Importantly, depletion of this long ncRNA, called ncRNA-al (activating long ncRNA 1), results in decreased ECM1 levels (Fig. 3C), suggesting a direct activating function of ncRNA-al on its neighboring gene.

ECM1 and ncRNA-a1 are located close to each other $(2 \mathrm{~kb})$, and the observed positive regulation of ECM1 by ncRNA-a1 could be explained if the two genes were components of the same transcript. Using PCR analysis of cDNA with primers spanning the two transcripts (Fig. 4A), we could not detect a transcript consisting of both ECM1 and ncRNA-al (Fig. 4B), although the region was readily amplified from genomic DNA (Fig. 4C). These results indicate that ncRNA-al is an independent transcription unit that can regulate the activity of ECM1.

\section{RNA-DEPENDENT REGULATION OF PROTEIN-CODING GENES}

A regulatory function of long ncRNAs on their surrounding genes is consistent with the present experimental observations on the mechanism of the function of long ncRNAs in processes such as imprinting and $\mathrm{X}$ inactivation (Mattick 2009). Functional knockdown of seven different ncRNAs using multiple cell lines revealed their regulatory role in activating expression of the neighboring protein-
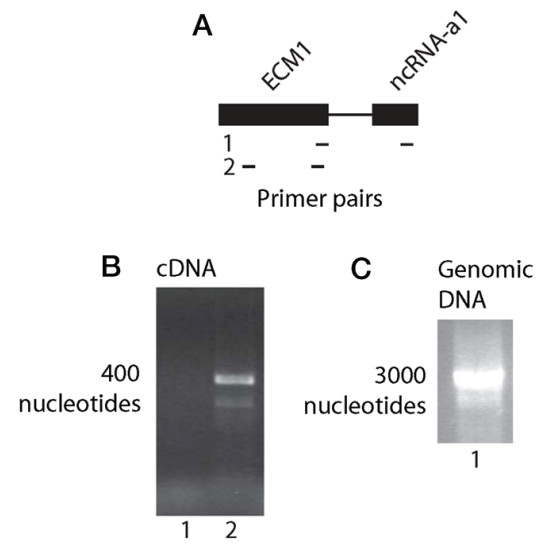

Figure 4. $(A)$ ECM1 and ncRNA-al genomic distance and location of primers used. (Thick black bars) The entire region of the genes including exons and introns. $(B)$ PCR from cDNA with the primer pairs indicated in $A$. (C) PCR from genomic DNA using primer pair 1 indicated in $A$. (Reprinted, with permission, from Ørom et al. 2010 [CElsevier].)

coding genes (Ørom et al. 2010). These include the genes KLHL12, ROCK2, TAL1, CMPK1, Snai2, and Snai1 regulated by ncRNA-a2 through ncRNA-a7, respectively. Snail regulation by ncRNA-a7 is shown as an example in Figure $5 \mathrm{~A}$. Snail is a regulator of epithelial-to-mesenchymal transition that is involved in cell migration (Savagner et al. 2001; Barrallo-Gimeno and Nieto 2005). Knockdown of ncRNA-a7 in A549 cells represses the expression of Snail specifically and diminishes cell migration to levels similar to that seen when knocking down Snail (Fig. 5B). These results indicate that ncRNA-a7 serves as a transcriptional enhancer of Snail.

A functional characterization of ncRNAa7 was performed using reporter assays with the ncRNA-a7 in a heterologous promoter driving firefly luciferase expression.

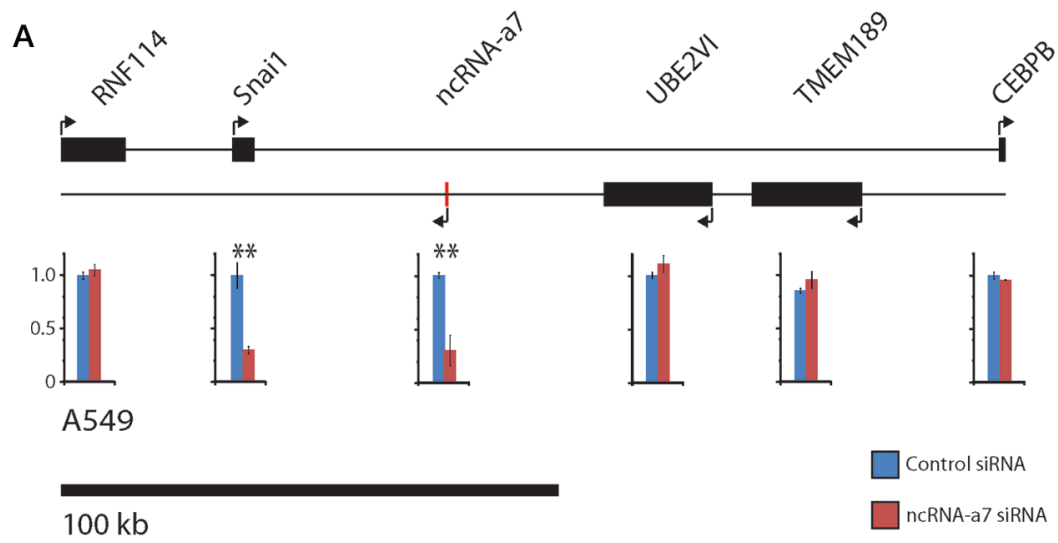

Figure 5. The long ncRNA ncRNA-a7 is an enhancer of Snail. (A) Snail genomic locus is depicted with thick black bars representing gene-encoding regions and showing relative expression levels of the genes in the Snail locus before (blue) and after (red) knockdown of ncRNA-a7. Scale bar corresponds to $100 \mathrm{~kb}$. All experiments are done in triplicate. $(* *) p<$ 0.01 with one-tailed Student's $t$-test. (B) Cellular migration of A549 cells with control transfected siRNA (left), knockdown of Snail (middle), or knockdown of ncRNA-a7 (right). (Reprinted, with permission, from Ørom et al. 2010 [CElsevier].)
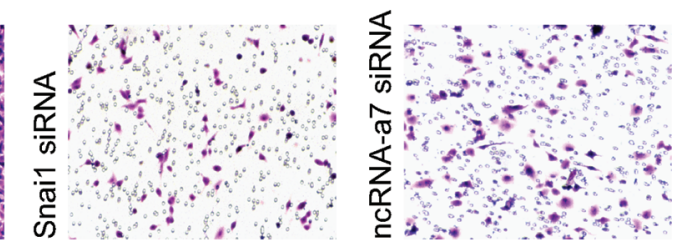
A

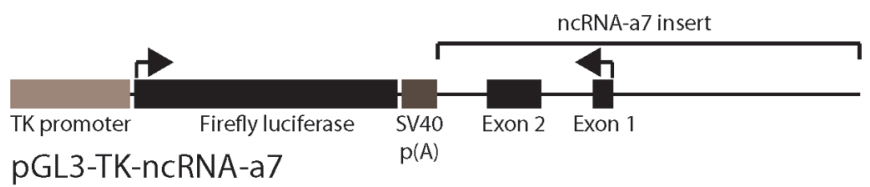

B

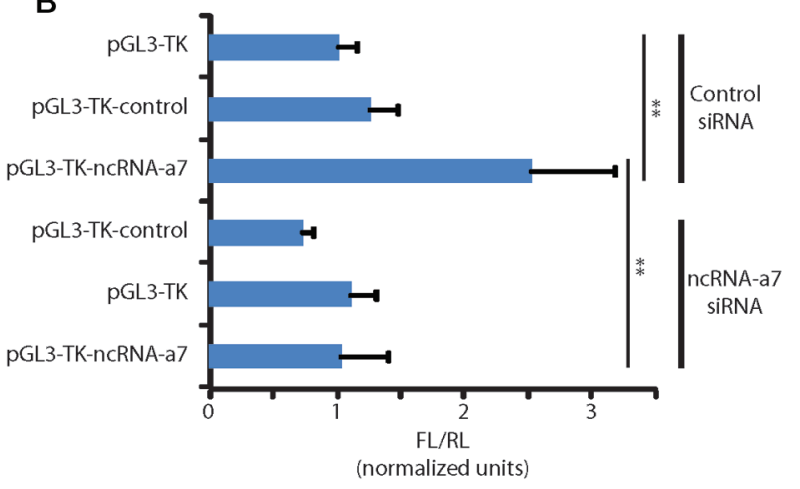

C

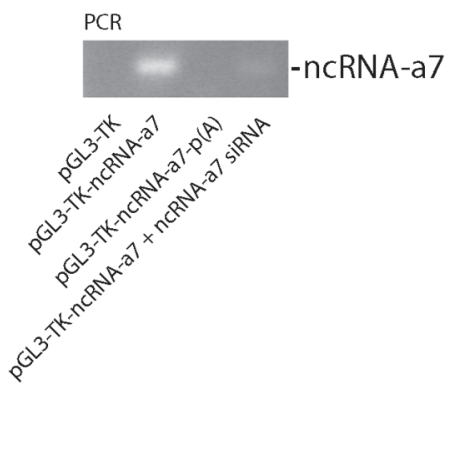

D

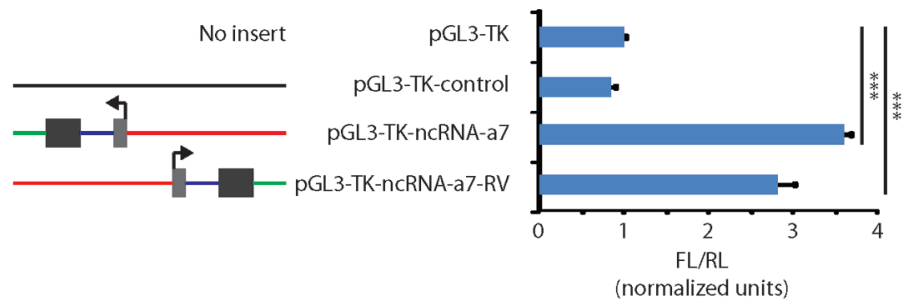

E

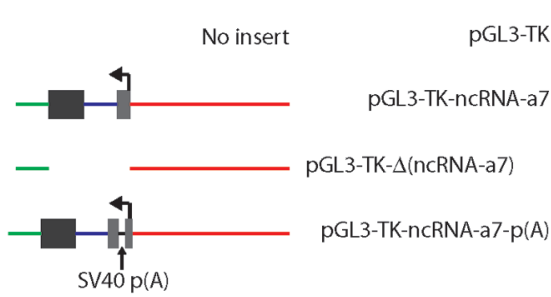

(normalized units)

Figure 6. RNA-dependent regulation of Snail by ncRNA-a7. A reporter vector was cloned containing the firefly luciferase driven by a TK promoter, and the activating RNA, ncRNA-a7, was inserted 3' to the reporter in its endogenous orientation with respect to Snail, as shown in $A$. (B) Luciferase reporter assay with control vectors (pGL3-TK and pGL3-TK-control) and ncRNA-a7-containing reporter vector, with and without knockdown of ncRNA-a7. (C) Semiquantitative PCR of ncRNA-a7 expression from control vector (pGL3TK), ncRNA-a7-containing reporter, reporter with ncRNA-a7 transcription disrupted by insertion of a premature polyadenylation signal in the first exon [pGL3-TK-ncRNA-a7-p(A)], and the ncRNA-a7 reporter vector after knockdown of ectopically expressed ncRNA-a7. $(D)$ Luciferase reporter assay with ncRNA-a7 inserted in both directions respective to luciferase. $(E)$ Deletion analysis and luciferase assay with constructs containing the ncRNA-a7 promoter, but not transcript [pGL3-TK- $\Delta$ (ncRNA-a7) or pGL3-TKncRNA-a 7-p (A)]. All values are shown as firefly luciferase values normalized to a transfection control expressing $R$. reniformis luciferase (FL/RL). All luciferase assays were done in six replicates. $(* * *) p<0.001 ;(* *) p<0.01$ by one-tailed Student's $t$-test. (Reprinted, with permission, from Ørom et al. 2010 [CElsevier].)

The overall design of the construct is shown in Figure 6A. Luciferase reporter assays with a cotransfected Renilla reniformis luciferase reporter vector (pRL-TK) in HEK293 cells show a threefold enhancement of the luciferase activity when the ncRNA-a7 is expressed in the $3^{\prime}$ orientation compared to the reporter gene (Fig. 6B, upper portion). The ncRNA-a7-mediated enhancement of gene expression was abrogated following the depletion of ncRNA-a7 (Fig. $6 \mathrm{~B}$, lower part), showing an RNA-dependent enhancing activity mediated by the ncRNA-a7 RNA full-length transcript. The overexpression of the ncRNA-a7 transcript from the pGL3-TK-ncRNA-a7 reporter was verified with semiquantitative PCR (Fig. 6C). Moreover, the efficiency of knockdown using siRNA and premature termination of 
transcription by insertion of a strong polyadenylation signal in the ncRNA-a7 encoding region is shown in Figure 6C. Both treatments diminished the transcriptional enhancement by ncRNA-a7 (Ørom et al. 2010).

Transcriptional enhancers have been defined as specific DNA regulatory elements modulating transcription from long distances (Banerji et al. 1981, 1983; Gillies et al. 1983; Kong et al. 1997; Heintzman et al. 2009). An important feature of enhancers is their orientation independence. Indeed, the efficiency of the enhancer function is independent of whether it is placed upstream of or downstream from the target promoter (Kong et al. 1997). Switching the direction of the ncRNA-a7 downstream from luciferase (pGL3-TK-ncRNA-a7-RV) results in similar levels of enhancing activity as that shown with the original orientation with respect to Snail (Fig. 6D). These results show the orientation independence of ncRNA-a on their enhancing properties and suggest a similar function for ncRNA-a and classically described enhancer elements. To further verify that ncRNA-a7 is the active component of the transcriptional enhancement, we constructed reporters in which ncRNA-a7 sequences were either shortened by placing a strong polyadenylation signal within the ncRNA-a7 genomic region within exon 1 or deleting the sequence encoding the ncRNA-a 7 transcript but maintaining the promoter region and downstream sequences (Fig. $6 \mathrm{E})$. Both modifications result in loss of increased gene expression compared to constructs in which ncRNA-a7 is expressed, supporting the notion that ncRNA-a7 is an enhancer of Snail transcription in an RNA-dependent way, requiring the full-length ncRNA-a7 transcript.

\section{CONCLUSIONS}

Long-distance regulation of transcription has gained recent attention with the identification of genome-wide putative enhancer elements based on chromatin marks (Heintzman et al. 2007, 2009; Visel et al. 2009) and the recent observations using mouse neurons that some enhancer elements are associated with ncRNAs (Kim et al. 2010). We report that a set of expressed long ncRNAs displays enhancer-like properties in human cell lines. It is important to note that the reported set of ncRNAs is fundamentally different from those reported in the mouse brain. Although the activating ncRNAs described in this study are predominantly spliced and polyadenylated, the mouse brain ncRNAs were reported to be nonpoladenylated. Nevertheless, both studies suggest a tantalizing proposal that transcriptional enhancers are transcribed and that such transcripts mediate the transcriptional stimulatory activity.

Using diverse experiments, we show the ncRNA-a transcripts as being the functional molecules mediating the enhancing effect. Such enhancer-like activities of long ncRNAs could be a widely used mechanism to regulate gene expression. Characterizing the mechanism by which ncRNA activation occurs will be an important step in understanding this phenomenon. We favor a mechanism akin to that of imprinting, in which a long ncRNA targets the neighboring genes in cis to bring about increased expres- sion. This could be achieved through the recruitment of a transcriptional activator, a basal transcription factor, or a chromatin-remodeling factor. Similar to the diverse functions of proteins, long ncRNAs may have multiple roles in the regulation of gene expression, of both protein-coding genes and other short and long ncRNAs.

It is important to indicate that the GENCODE annotation used in this study encompasses only a third of the human genome. The number of long ncRNAs in human cells is likely much higher and may equal or even surpass the number of protein-coding genes. The set of long ncRNAs we have defined from the HAVANA annotation excludes all ncRNAs associated with protein-coding genes and their promoters, and in this regard, it defines a new class of long ncRNAs in human cells, with some similarities to recently described lincRNAs in mouse (Guttman et al. 2009) and human (Khalil et al. 2009), and enhancerRNA (eRNA) described in the mouse brain (Kim et al. 2010). However, the overlap between the GENCODE-defined transcripts and those of lincRNAs is very small. Clearly, much more work is needed to catalog and characterize the ncRNAs in the mammalian systems. The next few years will be an exciting time for the analysis of ncRNAs in the variety of model organisms.

\section{ACKNOWLEDGMENTS}

Thanks to the HAVANA team for use of their genome annotation. We also thank the CRG Genomic Facility and the Functional Genomics Core Facility at Wistar and the University of Pennsylvania for expertise in microarray analysis. U.A.Ø. is supported by a grant from the Danish Research Council. R.G. was supported through the Spanish ministry and the National Institutes of Health (NIH), and R.S. was supported by a grant from the NIH (GM 079091).

\section{REFERENCES}

Banerji J, Rusconi S, Schaffner W. 1981. Expression of a $\beta$-globin gene is enhanced by remote SV40 DNA sequences. Cell 27: 299-308.

Banerji J, Olson L, Schaffner W. 1983. A lymphocyte-specific cellular enhancer is located downstream of the joining region in immunoglobulin heavy chain genes. Cell 33: 729-740.

Barrallo-Gimeno A, Nieto MA. 2005. The Snail genes as inducers of cell movement and survival: Implications in development and cancer. Development 132: 3151-3161.

Barski A, Cuddapah S, Cui K, Roh TY, Schones DE, Wang Z, Wei G, Chepelev I, Zhao K. 2007. High-resolution profiling of histone methylations in the human genome. Cell 129: 823-837.

Birney E, Stamatoyannopoulos JA, Dutta A, Guigo R, Gingeras TR, Margulies EH, Weng Z, Snyder M, Dermitzakis ET, Thurman RE, et al. 2007. Identification and analysis of functional elements in 1\% of the human genome by the ENCODE pilot project. Nature 447: 799-816.

Blanco E, Parra G, Guigó R. 2007. Using geneid to identify genes. Curr Protoc Bioinformatics 18: 4.3.1-4.3.28.

Cheng J, Kapranov P, Drenkow J, Dike S, Brubaker S, Patel S, Long J, Stern D, Tammana H, Helt G, et al. 2005. Transcriptional maps of 10 human chromosomes at 5-nucleotide resolution. Science 308: 1149-1154.

Core LJ, Lis JT. 2008. Transcription regulation through promoterproximal pausing of RNA polymerase II. Science 319: 17911792.

Gillies SD, Morrison SL, Oi VT, Tonegawa S. 1983. A tissue-spe- 
cific transcription enhancer element is located in the major intron of a rearranged immunoglobulin heavy chain gene. Cell 33: $717-728$.

Guttman M, Amit I, Garber M, French C, Lin MF, Feldser D, Huarte M, Zuk O, Carey BW, Cassady JP, et al. 2009. Chromatin signature reveals over a thousand highly conserved large noncoding RNAs in mammals. Nature 458: 223-227.

Harrow J, Denoeud F, Frankish A, Reymond A, Chen CK, Chrast J, Lagarde J, Gilbert JG, Storey R, Swarbreck D, et al. 2006. GENCODE: Producing a reference annotation for ENCODE. Genome Biol (suppl. 1) 7: S4.1-S4.9.

Heintzman ND, Stuart RK, Hon G, Fu Y, Ching CW, Hawkins RD, Barrera LO, Van Calcar S, Qu C, Ching KA, et al. 2007. Distinct and predictive chromatin signatures of transcriptional promoters and enhancers in the human genome. Nat Genet 39: 311-318.

Heintzman ND, Hon GC, Hawkins RD, Kheradpour P, Stark A, Harp LF, Ye Z, Lee LK, Stuart RK, Ching CW, et al. 2009. Histone modifications at human enhancers reflect global cell-typespecific gene expression. Nature 459: 108-112.

Kapranov P, Cheng J, Dike S, Nix DA, Duttagupta R, Willingham AT, Stadler PF, Hertel J, Hackermuller J, Hofacker IL, et al. 2007. RNA maps reveal new RNA classes and a possible function for pervasive transcription. Science 316: 1484-1488.

Khalil AM, Guttman M, Huarte M, Garber M, Raj A, Rivea Morales D, Thomas K, Presser A, Bernstein BE, van Oudenaarden A, et al. 2009. Many human large intergenic noncoding RNAs associate with chromatin-modifying complexes and affect gene expression. Proc Natl Acad Sci 106: 11667-11672.

Kim TK, Hemberg M, Gray JM, Costa AM, Bear DM, Wu J, Harmin DA, Laptewicz M, Barbara-Haley K, Kuersten S, et al. 2010. Widespread transcription at neuronal activity-regulated enhancers. Nature 465: 182-187.

Kong S, Bohl D, Li C, Tuan D. 1997. Transcription of the HS2 enhancer toward a cis-linked gene is independent of the orientation, position, and distance of the enhancer relative to the gene. Mol Cell Biol 17: 3955-3965.

Lunter G, Ponting CP, Hein J. 2006. Genome-wide identification of human functional DNA using a neutral indel model. PLoS Comput Biol 2: e5. doi: 10.1371/journal.pcbi.0020005.

Marques AC, Ponting CP. 2009. Catalogues of mammalian long noncoding RNAs: Modest conservation and incompleteness. Genome Biol 10: R124. doi: 10.1186/gb-2009-10-11-r124.

Mattick JS. 2009. The genetic signatures of noncoding RNAs. PLoS Genet 5: e1000459. doi: 10.1371/journal.pgen.1000459.

Mikkelsen TS, Ku M, Jaffe DB, Issac B, Lieberman E, Giannoukos G, Alvarez P, Brockman W, Kim TK, Koche RP, et al. 2007. Genome-wide maps of chromatin state in pluripotent and lineage-committed cells. Nature 448: 553-560.

Ørom U, Derrien T, Beringer M, Gumireddy K, Gardini A, Bussotti G, Lai F, Zytnicki M, Notredame C, Huang Q, et al. 2010. Long non-coding RNAs with enhancer-like function in human cells. Cell 143: 46-58.

Parra G, Blanco E, Guigo R. 2000. GeneID in Drosophila. Genome Res 10: 511-515.

Ponjavic J, Ponting CP, Lunter G. 2007. Functionality or transcriptional noise? Evidence for selection within long noncoding RNAs. Genome Res 17: 556-565.

Ponting CP, Oliver PL, Reik W. 2009. Evolution and functions of long noncoding RNAs. Cell 136: 629-641.

Preker P, Nielsen J, Kammler S, Lykke-Andersen S, Christensen MS, Mapendano CK, Schierup MH, Jensen TH. 2008. RNA exosome depletion reveals transcription upstream of active human promoters. Science 322: 1851-1854.

Rinn JL, Kertesz M, Wang JK, Squazzo SL, Xu X, Brugmann SA, Goodnough LH, Helms JA, Farnham PJ, Segal E, Chang HY. 2007. Functional demarcation of active and silent chromatin domains in human HOX loci by noncoding RNAs. Cell 129: 1311-1323.

Savagner F, Franc B, Guyetant S, Rodien P, Reynier P, Malthiery Y. 2001. Defective mitochondrial ATP synthesis in oxyphilic thyroid tumors. J Clin Endocrinol Metab 86: 4920-4925.

Seila AC, Calabrese JM, Levine SS, Yeo GW, Rahl PB, Flynn RA, Young RA, Sharp PA. 2008. Divergent transcription from active promoters. Science 322: 1849-1851.

Visel A, Blow MJ, Li Z, Zhang T, Akiyama JA, Holt A, PlajzerFrick I, Shoukry M, Wright C, Chen F, et al. 2009. ChIP-seq accurately predicts tissue-specific activity of enhancers. Nature 457: 854-858.

Wan LB, Bartolomei MS. 2008. Regulation of imprinting in clusters: Noncoding RNAs versus insulators. Adv Genet 61: 207-223. 


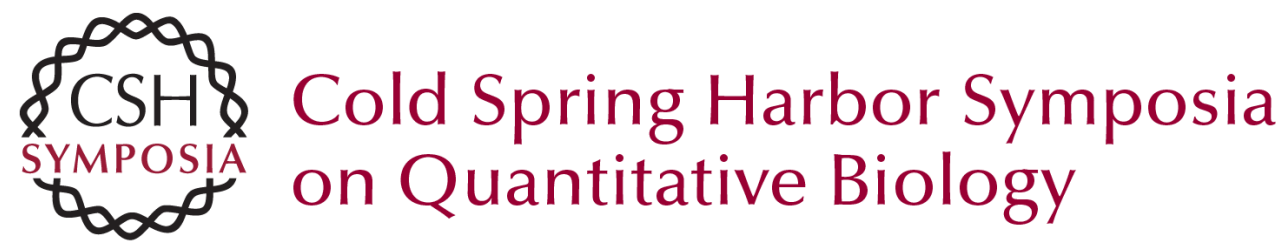

\title{
Long Noncoding RNAs as Enhancers of Gene Expression
}

\author{
U.A. Ørom, T. Derrien, R. Guigo, et al.
}

Cold Spring Harb Symp Quant Biol 2010 75: 325-331 originally published online April 18, 2011 Access the most recent version at doi:10.1101/sqb.2010.75.058

References This article cites 31 articles, 10 of which can be accessed free at: http://symposium.cshlp.org/content/75/325.full.html\#ref-list-1

\section{License}

Email Alerting Receive free email alerts when new articles cite this article - sign up in Service the box at the top right corner of the article or click here. 